\title{
Bauman e o Capitalismo. Quando a sociedade se transforma no hospedeiro
}

\author{
Bauman y el capitalismo. Cuando la sociedad se transforma en el huésped
}

Bauman and Capitalism. When society becomes the host

Saddam Mohamad Harb ${ }^{1}$

\begin{abstract}
Resumo
A presente resenha critica tem por objetivo analisar a obra de Zygmunt Bauman intitulada Capitalismo Parasitário, em que o sociólogo discorre sobre o modelo do capitalismo na nossa sociedade e compara com a modernidade líquida. Uma pesquisa qualitativa, portanto, em que se ateve na obra do autor na qual concluiu-se que o modelo do capitalismo não é visto com bons olhos pelo mesmo, razão pela qual ele descreve sua atuação como de um parasita.
\end{abstract}

Palavras-Chave: Zygmunt Bauman, Capitalismo, Modernidade Liquida, Parasita

\section{Resumen}

La presente reseña crítica tiene por objetivo analizar la obra de Zygmunt Bauman intitulada Capitalismo Parasitario, en la que el sociologo discurre sobre el modelo del capitalismo en nuestra sociedad y compara con la modernidad neta. Una investigación cualitativa, por lo tanto, en que se fue en la obra del autor en la que se concluyó que el modelo del capitalismo no es visto con buenos ojos por el mismo, razón por la cual él describe su actuación como de un parásito.

Palabras claves: Zygmunt Bauman, Capitalismo, Modernidad Liquida, Parasita

\begin{abstract}
The present critical review aims to analyze the work of Zygmunt Bauman entitled Parasitarian Capitalism, in which the sociologist discusses the model of capitalism in our society and compares with liquid modernity. A qualitative research, therefore, is based on the author's work in which it was concluded that the model of capitalism is not favorably viewed by it, which is why it describes its performance as a parasite.

Keywords: Zygmunt Bauman, Capitalism, Liquid Modernity, Parasite.
\end{abstract}

BAUMAN, Zygmunt. Capitalismo Parasitário. Rio de Janeiro: Zahar, 2005. 80 páginas.

Zygmunt Bauman é um dos mais influentes sociólogos da atualidade. Muito embora tenha morrido recentemente, deixou obras que representam verdadeiros legados para quem considera-se estudioso de ciências humanas e sociais. Entre seus mais influentes temas, estão a questão da modernidade líquida, globalização, abordou ainda, a questão da sociedade contemporânea e suas várias facetas, a questão dos refugiados na qual outorgou a alcunha de

\footnotetext{
${ }^{1}$ Aluno da graduação do curso de Direito da turma do último ano da FURG. E-mail: saddam.mh@gmail.com.
} 
estranhos que batem a nossa porta, holocausto e a sobrevivência do preconceito com os judeus na atualidade, e por fim, o modelo econômico do capitalismo, tecendo severas críticas ao modelo econômico hegemônico no planeta.

O autor inicia o primeiro capítulo expondo suas convicções sobre o modelo do capitalismo. Com uma linguagem simplória, mas não menos rica em conteúdo, Bauman o intitula de Capitalismo Parasitário, na qual compara o modelo econômico a um vírus que vê seu progresso na miséria de alguém. Nas palavras do autor:

Sem meias palavras, o capitalismo é um sistema parasitário. Como todos os parasitas, pode prosperar durante certo período, desde que encontre um organismo ainda não explorado que lhe forneça alimento. Mas não pode fazer isso sem prejudicar o hospedeiro, destruindo assim, cedo ou tarde, as condições de sua prosperidade ou mesmo de sua sobrevivência. (BAUMAN, 2005, p.02)

No transcorrer do capítulo inicial o autor critica o modelo vigente de atuação das instituições bancárias, na qual se assemelham a agiotas assegurados pela lei. A analogia é verossímil, e as razões para se crer nisso são vastas. Inicialmente, são instituições que emprestam dinheiro a juros muito altos, e com datas prefixados de adimplemento, para exemplificar essa situação, o autor cita exemplos publicados no jornal inglês The Guardian.

Por fim, Bauman tece considerações sobre a cooperação entre o Estado e o modelo econômico, na qual segundo ele culmina na "mercadorização" das relações, incluindo as relações do trabalho, na qual é gerida em favor dos interesses dos mercados. Muito embora o livro já tenha alguns anos de vida, a afirmação é pertinente pois, vivemos tempos de relativização dos direitos trabalhistas no nosso país, o que, com o favorecimento da terceirização, e os inúmeros óbices a reclamatórias laborais, tais medidas constituem-se como fortes exemplos para os dizeres do autor.

Para Bauman, o alinhamento entre o Estado (governo) e o modelo econômico do capitalismo são nocivos as relações sociais, pois impõe a competição entre os homens na busca constante por lucros, sem contar na exploração do trabalhador ${ }^{2}$. Dessa maneira, é por

\footnotetext{
${ }^{2}$ Sobre isso, Madel ressalta que a diferenciação do estado comandado pela burguesia de estados anteriores é a dominação de classes, generalização da produção e a concorrência, nas palavras dele: "O Estado burguês se distingue de todas as formas anteriores de dominação de classe por uma peculiaridade da sociedade burguesa que é inerente ao próprio modo de produção capitalista. O isolamento das esferas públicas e privadas da sociedade, que é consequência da generalização sem igual da produção de mercadorias, da propriedade privada e da concorrência de todos contra a todos. " (MANDEL, 1982, p. 336)
} 
lógico a constatação de que a dominação de classe, bem como luta de classes não apenas existiu, mas ganhou maior destaque na era capitalista do estado.

Quando nos referimos a gênero a situação se torna ainda mais agravante, pois, ainda no nosso século, testemunhamos uma grave desigualdade de gênero. No campo laboral, as mulheres sofrem constantemente com constrangimentos, exploração e salários inferiores. Muito embora Bauman não mencione a questão de gênero na obra em cotejo, o que em uma primeira vista é preocupante pois tratou-se de um dos pouquíssimos temas que o autor não se debruçou durante toda a sua vida intelectual, mas contemporaneamente é possível fazer a analogia entre os temas.

Assim, quando menciona a mercadorização das relações sociais, por além da exploração do proletário e das camadas sociais, Bauman tenciona que o modelo do capitalismo não é nada se não um hospedeiro indesejado que se nutre e sobrevive às custas do sacrifício de outro ser ou modelo. Daí, que, a derrocada desse modelo não é apenas a conquista dos direitos sociais, mas sim a luta por uma nova ordem societária.

No segundo capitulo intitulado "Cultura da Oferta", o autor analisa a imposição da oferta na fase liquido - moderna da sociedade em que nos encontramos. Segundo o autor, a cultura tem como parâmetro o grau de liberdade de escolha dos indivíduos, tendo certa exigência de atuação. De tal afirmativa, Bauman lembra Pierre Bordieu, para quem "A cultura vive de sedução, não de regulamentação; de relações públicas, não de controle policial; da criação de novas necessidades/desejos/exigências, não de coerção." (p.28)

Este capitulo é subdividido em dois sub-capítulos. O primeiro é intitulado "Novos Desafios para a Educação", onde ou autor trabalha com a descartabilidade, seja de relações humanas, materiais e principalmente de conhecimentos. As coisas não estão em nossa sociedade para ficar, e sim para serem usadas e após isso, descartadas, por isso, a frase mais corriqueira falada pelas pessoas mais velhas de que "o que se estuda, ninguém pode te tirar", poderia ser algo reconfortante em tempos de outrora, mas atualmente, é uma ideia nefasta.

Ao longo de muitas de suas obras, o autor deteve-se sobre a descartabilidade em suas várias faces. Já fora abordado a situação dos refugiados, na sua mais recente obra, abordou a questão dos efeitos colaterais em guerras no Oriente Médio e continente africano, na qual segundo Bauman, são pessoas mortas que não se encontravam na margem de erros em operações militares. Nesse momento, o autor adentra nas Universidades e instituições de 
ensino, na qual, demonstra que a perspectiva de que os conhecimentos vêm para ficar e enriquecer o individuo, na contemporaneidade, parece ser uma ameaça, nas palavras dele: "A ideia de que a educação pode consistir em um "produto" feito para ser apropriado e conservado é desconcertante, e sem dúvida não depõe a favor da educação institucionalizada. " (p. 32)

De maneira semelhante, Bauman faz analogia entre as universidades e os quartéis e pan-ópticos, presídio idealizado por Jeremy Bentham, em que é repleto de regras a serem seguidas e de pessoas incumbidas de vigiarem outras pessoas. Assim são as universidades e colégios em geral, que seguem à risca o programa de ensino. Ainda, os próprios pesquisadores de mestrado e doutorado das universidades são privados de pensarem fora do projeto estipulado, estando rigorosamente presos a metodologia estipulada e tendo que findar a pesquisa em tempo pré-determinado. Definitivamente, o rigor cientifico majoritário presta um desserviço à comunidade acadêmica, servindo apenas para regulamentar a gestão das bolsas de pesquisa nas universidades, consistindo em um empecilho para os pesquisadores.

O autor opta por não apontar os erros das instituições de ensino, mas apenas nas consequências de se ter uma sociedade com indivíduos com expectativas tão voláteis e imediatistas. A genialidade de Bauman centra-se justamente neste ponto. O livro foi lançado em 2005, e o sociólogo antecipa as maneiras de atuação da sociedade, na qual a lógica pensada para o mercado, sob a égide do modelo capitalista, vê o progresso do modelo econômico com a deterioração do ensino, em uma atuação parasitária e condicionante.

No segundo sub-capítulo, intitulado "A relação professor/aluno na fase líquidomoderna" o autor aborda um tema que já foi abordado na psicologia social, qual seja, a difícil relação entre pessoas mais velhas e mais novas na sociedade moderna. Essa é incompreensão recíproca na opinião do autor e adentra tanto os lares, quanto as escolas, culminando na famigerada frase "por que nо теи tempo...". Este embate sempre existiu, mas ganha novos contornos à medida que o tempo passa, principalmente com o advento da tecnologia, na qual, a rapidez e a volatilidade tornam-se presentes nos nossos tempos, fortalecendo a descartabilidade, pois, os relacionamentos virtuais são tidos como algo que é para ser usado e após o esgotamento, jogado fora, nas palavras do autor:

O mundo off-line convida os jovens a estar em constante movimento. Mas solicitações deste tipo de pouco adiantariam se não fosse a capacidade, baseada na eletrônica, de multiplicar os encontros interindividuais, transformando cada um deles num ato rápido, superficial, de tipo "use e jogue fora". Relações virtuais são equipadas com a tecla "delete" e com "antispam", mecanismos que protegem das 
consequências incômodas (e sobretudo dispendiosas em termos de tempo) das interações mais profundas. (BAUMAN, 2005, 70)

O terceiro capítulo possui um título sugestivo e impactante: "A Sociedade do Medo" na qual o autor responde a uma série de perguntas sobre os temores que assolam a sociedade atual. Em todos os locais de fala o autor demonstra onde pretende chegar, pois expõe os demônios da sociedade do medo, na qual, a volatilidade das relações, dos empregos, dos salários e do status social torna nossas noites intranquilas, bem como; o acúmulo dessas emoções vestem nossos dias de insegurança e nebulosidade. "Os medos são muitos e diferentes, mas eles alimentam uns aos outros. A combinação desses medos cria um estado na mente e nos sentimentos que só pode ser descrito como ambiente de insegurança." (p.72)

O quarto capítulo intitulado "Corpo em Contradição" o autor responde à pergunta "Até que ponto a sociedade de consumidores, baseada na liquidez, contribui para o aparecimento de patologias específicas de nosso tempo, como a bulimia, por exemplo?" em que expõe as patologias como evidências de contradições em uma sociedade dominada por desejos imediatistas e descartáveis. A anorexia está relacionada a um modo de pensar que privilegia a sensação de prazer e a aptidão física juntas. A bulimia expressa a contradição de uma sociedade com desejos, razão por que proporciona um deleite fabuloso, mas ao mesmo tempo, impõe padrões de forma esbeltos e em forma. Ambas patologias se configuram em respostas ao estilo de vida de pessoas rodeada por ofertas, o que ocasiona a prevalência dos desejos e finda no consumo desenfreado.

O quinto capítulo intitulado "Um homem com esperanças", Bauman expõe suas aspirações para o futuro. Dotado de certo otimismo com uma possível mudança de paradigma da sociedade, assim como uma mudança para o consumo, não apenas de bens materiais, mas uma mudança de concepção no tocante a relacionamentos, para que sejam mais duradouros e pessoais, ao contrário do que se observa, ou seja, rápidos e virtuais.

Da leitura desta obra o que se obtém como principal conclusão é que o modelo econômico do Capitalismo progride em nossa sociedade camuflado por inúmeras armadilhas. Seja pelo consumo exacerbado, seja através das relações humanas cada vez mais virtuais e, portanto, artificiais, seja na educação e na relação entre professores e alunos, seja lidando com padrões de beleza e doenças em decorrência disso. O modelo anda por todos os lados "parasitoriamente", tornando a sociedade seu imenso hospedeiro. As conclusões disso, como afirma a biologia, e ratifica o sociólogo é a morte, o fim. 
O grande legado de Bauman para a contemporaneidade foi deixar suas reflexões sobre o consumo, o modelo econômico do capitalismo, a liquidez da vida moderna, os refugiados e o direito internacional, a política, mas principalmente, sobre a vida como um todo. $\mathrm{O}$ autor deixa transparecer que compreender a sociologia requer uma profunda compreensão da vida humana, eis aí seu mais importante legado, do qual o mundo sentirá falta. Pela leitura, não apenas desta obra, mas de muitas outras, resta a imensa gratidão pela oportunidade de desfrutar de uma obra rica em conteúdo em conselhos.

\section{Referências}

BAUMAN, Zygmunt. Babel: entre a incerteza e a esperança. Rio de Janeiro: Zahar, 2016.

BAUMAN, Zygmunt, Modernidade e holocausto. Tradução Marcus Penchel. Rio de Janeiro: Zahar Editores, 1998

BAUMAN, Zygmunt. Vidas desperdiçadas. Carlos Alberto Medeiros. Rio de Janeiro: Zahar Editores, 2005.

BAUMAN, Zygmunt. Globalização: as consequências humanas. Tradução: Marcus Penchel. Jorge Zahar Ed.: Rio de Janeiro, 1999.

BAUMAN, Zygmunt. Vida Em Fragmentos: Sobre a ética Pós-moderna. Rio de Janeiro: Zahar, 2005.

BAUMAN, Zygmunt Estranhos à Nossa Porta, Rio de Janeiro, Zahar, 2017, 123 pp.

LUXEMBURG, Rosa. The Accumulation of Capital. Monthly Review Press, 1951.

MANDEL, Ernest. O Estado na fase do capitalismo tardio. In: O capitalismo tardio. Trad.

Carlos Eduardo S. Matos et all. São Paulo: Abril Cultural. Os economistas, 1982.

Welzer, Harald. Guerras Climáticas - por que mataremos e seremos mortos no século 21. Madrid: Katz, 2010. 